\title{
Effect of different types of carbohydrate supplementation on glycogen supercompensation in rat skeletal muscle
}

\author{
Tomohiro SONOU ${ }^{1)}$, Shin TERADA ${ }^{2)}$, Michiyo KIMURA ${ }^{3)}$, Isao MURAOKA ${ }^{4}$, \\ Yoshio NAKAMURA ${ }^{4)}$, and Mitsuru HIGUCHI ${ }^{4}$ \\ ${ }^{1)}$ Graduate School of Human Sciences, Waseda University \\ ${ }^{2)}$ Consolidated Research Institute for Advanced Science and Medical Care, \\ Waseda University \\ ${ }^{3)}$ Department of Health and Nutrition, Faculty of Health and Welfare, \\ Takasaki University of Health and Welfare \\ ${ }^{4)}$ Faculty of Sport Sciences, Waseda University
}

Key Words: carbohydrate supplementation, glycogen, skeletal muscle, liver, exercise

\begin{abstract}
The purpose of this study was to examine the effects of glucose and sucrose supplement on glycogen accumulation in rat skeletal muscle and liver after exhaustive endurance exercise. Four- to five-week-old male Sprague-Dawley rats with an initial body weight ranging from 90 to $110 \mathrm{~g}$ were used for this study. All rats were trained by using a 7-day-long swimming exercise program, during which rats swam 6 h/day in two 3-h bouts separated by 45 min of rest. On the next day of the last training, all trained animals performed 240 min of swimming exercise with a weight equivalent to $3 \%$ of their body weight to deplete muscle and liver glycogen. After glycogen-depleting exercise, rats were given a rodent chow diet plus either $5 \%$ sucrose (SUC), $5 \%$ glucose (GLU) or water (CON) for $6 \mathrm{~h}$ or $24 \mathrm{~h}$. Despite equal amount of carbohydrate intake, glycogen concentration in rat epitrochlearis muscle of the GLU group rats was significantly higher compared with those observed in the CON $(\mathrm{p}<0.001)$ and the SUC groups $(\mathrm{p}<0.01)$. No significant difference in liver glycogen was observed among three groups. These results indicate that glucose supplementation rather than sucrose supplementation efficiently promotes glycogen supercompensation in rat skeletal muscle.
\end{abstract}

スポーツ科学研究, $4,85-92,2007$ 年, 受付日: 2007 年 6 月 7 日, 受理日: 2007 年 10 月 6 日

連絡先：Mitsuru HIGUCHI, Faculty of Sport Sciences, Waseda University,

2-579-15, Mikajima Tokorozawa, Saitama, 359-1192, Japan

mhiguchi@waseda.jp 


\section{INTRODUCTION}

Muscle glycogen is known to be an essential source of energy during intense, prolonged exercise. In this regard, it has been demonstrated that perception of fatigue parallels the decline of glycogen in human skeletal muscle, and that aerobic endurance is related to the pre-exercise muscle glycogen store (Bergstrom et al. 1967, Ahlborg et al. 1967). As clearly shown in the classic human study by Bergstrom and Hultman (1966), a glycogen-depleting bout of exercise followed by a high carbohydrate diet results in an increase in muscle glycogen to levels well above those normally seen in the fed state. This supranormal accumulation of muscle glycogen, a process referred to as glycogen supercompensation, is now an integral component of the preparation of endurance athletes for competition.

Previous studies have examined exercise-dietary regimens to enhance muscle glycogen supercompensation. Nakatani et al. (1997) reported that exercise training that induces an increase in muscle GLUT-4 content results in a large increase in the muscle glycogen supercompensation level after a glycogen-depleting bout of exercise in rats. In their study, rats were given not only Purina chow but also $5 \%$ sucrose in their drinking water ad libitum after glycogen depleting swimming exercise. The rationale for supplementation of sucrose was to ensure an adequate carbohydrate intake. However, to our knowledge, there have been few studies that examined the influence of the type of carbohydrate supplement consumed for glycogen supercompensation. Since glycemic index of glucose is known to be higher than sucrose (Foster-Powell and Miller 1995), it is likely that glucose efficiently stimulates pancreatic insulin secretion, resulting in higher glucose uptake and glycogen synthase activity. Therefore, we hypothesized that glucose supplementation may elevate the level of glycogen supercompensation to higher level than sucrose. In this context, the goal of the present investigation was to compare the effect of glucose and sucrose supplement on glycogen accumulation in rat skeletal muscle and liver after exhaustive exercise.

\section{MATERIALS AND METHODS}

\section{Animal care}

Four- to five-week-old male Sprague-Dawley rats (Crea Japan, Tokyo, Japan) with initial body weight ranging from 90-110 g were used for this study. All animals were housed in rooms lighted from 11:00 AM to 11:00 PM and maintained on an ad libitum diet of standard chow (CE-2, Crea Japan, Tokyo, Japan) and water. Room temperature was maintained at $20-22^{\circ} \mathrm{C}$.

Animals were familiarized to laboratory conditions for 3 days before experimentation and were accustomed to swimming for 10 min/day for 2 days. The Animal Studies Committee of the Waseda University School of Human Sciences approved this research

\section{Training protocol and glycogen depletion exercise bout}

All rats performed 7-day-long low-intensity prolonged swimming exercise training, as described by Terada et al. (2001). Eight rats swam simultaneously without a load for 6-h in two 3-h sessions separated by $45 \mathrm{~min}$ of rest in a barrel filled to a depth of $50 \mathrm{~cm}$ and an aver- 
age surface area of $150 \mathrm{~cm} 2 /$ rat. Water temperature was maintained at $35^{\circ} \mathrm{C}$ during swimming training. The rats performed the swimming training once a day from $\sim 2: 00 \mathrm{PM}$ to 9:00 PM for 7days. This training program has been regarded as the maximal stimulus for increase in GLUT-4, the isoform of glucose transporter, in muscle (Ren et al. 1994, Terada et al. 2001). On the last training day, swimming training was finished before 9:00 PM, and food was restricted to $8 \mathrm{~g} /$ rat after 10:00 PM the night before the glycogen depletion exercise bout.

Between 3:00 PM and 4:00 PM the next day (17-19h fasted), all training animals performed $240 \mathrm{~min}$ of swimming exercise with a weight equivalent to $3 \%$ of their body weight in a barrel (an average surface area of $150 \mathrm{~cm} 2 /$ rat) filled to a depth of $50 \mathrm{~cm}$, with water maintained at $35^{\circ} \mathrm{C}$. After the "glycogen-depleting" exercise, rats were given a rodent chow (CE-2) diet plus either $5 \%$ sucrose (SUC; $\mathrm{n}=6: 6 \mathrm{~h}$, $\mathrm{n}=8: 24 \mathrm{~h}$ ), $5 \%$ glucose (GLU; $\mathrm{n}=7: 6 \mathrm{~h}, \mathrm{n}=7$ : $24 \mathrm{~h}$ ) or water (CON; $n=6: 6 \mathrm{~h}, \mathrm{n}=7: 24 \mathrm{~h})$ for $6 \mathrm{~h}$ or $24 \mathrm{~h}$. Diet and water consumptions of two repletion periods were measured.

\section{Tissue collection}

After repletion period ( $6 \mathrm{~h}$ or $24 \mathrm{~h}$ after glycogen-depleting exercise), rats were anesthetized with an intraperitoneal injection of pentobarbital sodium $(5 \mathrm{mg} / 100 \mathrm{~g}$ body weight). Blood was then sampled via cardiac puncture and subsequently used for determination of plasma glucose concentration. Liver and epitrochlearis muscle were dissected out and were immediately freeze-clamped between aluminium plates pre-cooled in liquid nitrogen. All samples were kept at $-70^{\circ} \mathrm{C}$ until analysis. The rat epitrochlearis muscle was used for this research because it is extensively used during swimming, the form of exercise employed in the present study. This is evidenced by glycogen depletion, stimulation of glucose transport and increased insulin sensitivity in response to a bout of exercise and adaptive increases in GLUT-4 and hexokinase (Cartee et al. 1989, Ren et al. 1994, Young et al. 1987).

\section{Determination of plasma glucose concentra- tion}

Plasma glucose was determined by the glucose oxidase method with Glucose C II test wako (Wako Pure Chemical Industries, Ltd., Osaka, Japan).

\section{Analysis of muscle and liver glycogen con- centration}

Epitrochlearis and liver samples were weighed and then homogenized in $0.3 \mathrm{M}$ perchloric acid. Glycogen concentrations in epitrochlearis muscle and liver were determined by enzymatic methods according to Lowry and Passonneau (1972) after acid hydrolysis.

\section{Statistical analysis}

All values are expressed as mean \pm SD. Statistical analysis was performed using two-way analysis of variance (ANOVA) (Jandel Sigma Stat) to examine the effects of different types of sugar supplementation and time for recovery. Statistical significance was defined as $\mathrm{p}<0.05$. 
Table 1. Body weight, plasma glucose and plasma insulin concentration at 6-h and 24-h after a glycogen-depleting exercise.

\begin{tabular}{|lc|ccc|}
\hline & $\begin{array}{c}\text { Recovery } \\
\text { time }\end{array}$ & \multicolumn{3}{|c|}{ Group } \\
\cline { 3 - 5 } & $6 h$ & CON & GLU & SUC \\
\hline Body weight & $\left.6 h^{\dagger}\right)$ & $183 \pm 5$ & $182 \pm 9$ & $181 \pm 10$ \\
\hline Plasma glucose & $24 h^{\dagger}$ & $193 \pm 15$ & $192 \pm 10$ & $191 \pm 5$ \\
\hline$(m g / 100 m L)$ & $6 h$ & $205 \pm 16$ & $211 \pm 13$ & $245 \pm 69$ \\
\hline Plasma insulin & $24 h^{\ddagger}$ & $170 \pm 11$ & $185 \pm 38$ & $173 \pm 14$ \\
$(\mu g / m L)$ & $6 h$ & $81 \pm 72$ & $86 \pm 58$ & $93 \pm 79$ \\
\hline
\end{tabular}

Values are means \pm SD. CON; distilled water. SUC; $5 \%$ sucrose solution. GLU; $5 \%$ glucose solution. Significant effect of recovery time, ${ }^{\dagger} ;$ p $<0.01,{ }^{\star} ; p<0.001$, vs. $6 \mathrm{~h}$

\section{RESULTS}

\section{Body weight}

Table 1 showed the body weight (BW) at 6 $\mathrm{h}$ and $24 \mathrm{~h}$ after glycogen-depleting exercise. BW at $24 \mathrm{~h}$ after the exercise was significantly heavier than that observed at $6 \mathrm{~h}(\mathrm{p}<0.01)$. No significant difference in the average body weight was observed among three groups. The interaction between different types of sugar supplementation and time for recovery was not statistically significant.

\section{Plasma glucose and insulin concentration}

Plasma glucose concentration at $24 \mathrm{~h}$ of glycogen repletion period was significantly lower than that observed at $6 \mathrm{~h}(\mathrm{p}<0.001)$. Plasma glucose and insulin values were not affected by the different types of sugar supplementation (Table 1). No statistically significant interaction between different types of sugar supplementation and time for recovery was observed.

Table 2. Food, fluid, and total carbohydrate consumption during $6 \mathrm{~h}$ and $24 \mathrm{~h}$ recovery period.

\begin{tabular}{|lc|ccc|}
\hline & $\begin{array}{c}\text { Recovery } \\
\text { time }\end{array}$ & \multicolumn{3}{c|}{ Group } \\
\cline { 3 - 5 } & $6 h^{*}$ & CON & GLU & SUC \\
\hline Food intake & $24 h^{\ddagger}$ & $34.0 \pm 2.4^{* *}$ & $28.8 \pm 2.1$ & $16.4 \pm 0.6^{*}$ \\
$(g)$ & $6 h^{*}$ & $34.5 \pm 3.6^{*}$ & $31.8 \pm 2.0$ & $29.4 \pm 1.2$ \\
\hline Fluid intake & $24 h^{\ddagger}$ & $75.5 \pm 5.0 *$ & $65.5 \pm 5.2$ & $32.4 \pm 3.4$ \\
$(m L)$ & $6 h^{*}$ & $9.5 \pm 0.8$ & $9.6 \pm 0.5$ & $64.9 \pm 4.7$ \\
\hline Total CHO intake & $24 h^{\ddagger}$ & $17.2 \pm 1.2$ & $18.2 \pm 0.7$ & $9.9 \pm 0.4$ \\
$(g)$ & & & $18.2 \pm 0.6$ \\
\hline
\end{tabular}

Values are means \pm SD. CON; distilled water. SUC; $5 \%$ sucrose solution. GLU; $5 \%$ glucose solution.

Significant effect of recovery time, $\quad \neq ; p<0.001$ vs. $6 \mathrm{~h}$

Significant effect of supplementation, $\quad$ *; $p<0.01, \quad$ **; $p<0.001$, vs. GLU and SUC 


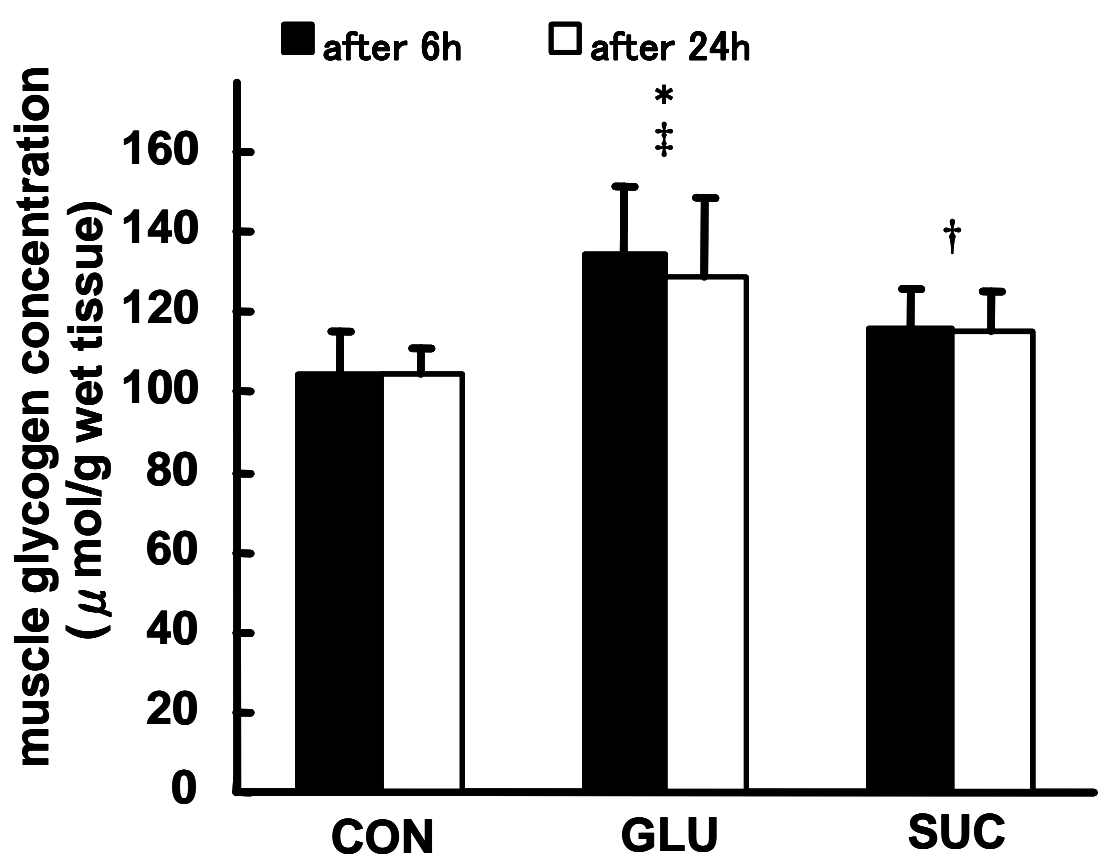

Fig.1. Effects of different carbohydrate supplements on muscle glycogen concentration in the rat epitrochlearis muscle at $6 \mathrm{~h}$ and $24 \mathrm{~h}$ after the depletion exercise. CON; distilled water. GLU; $5 \%$ glucose solution. SUC; $5 \%$ sucrose solution. Values are means $\pm S D$. There was significant effect of group $(p<0.001)$. $\dagger$ and $\ddagger$ indicate significant differences from the CON group at the level of $p<0.01$ and $p<0.001$, respectively. * indicates a significant difference from the SUC group at a level of $p<0.05$.

\section{Consumption of food, fluid and total carbo-} hydrate.

As shown in Table 2, food and fluid consumptions in the CON group were significantly higher compared with those observed in the GLU and SUC groups $(\mathrm{p}<0.001$; food, $\mathrm{p}<0.01$; fluid). There were no significant differences in food and fluid intake between the SUC and GLU groups. Calculated total carbohydrate intakes were not different among three groups. In these parameters, the interactions between different types of sugar supplementation and time for recovery were not statistically significant.

Table 3. Liver glycogen concentration at $6 \mathrm{~h}$ and $24 \mathrm{~h}$ after a glycogen-depleting exercise.

\begin{tabular}{|lc|ccc|}
\hline & $\begin{array}{c}\text { Recovery } \\
\text { time }\end{array}$ & \multicolumn{3}{c|}{ Group } \\
\cline { 3 - 4 } & $6 h$ & CON & GLU & SUC \\
\hline Liver glycogen & $437 \pm 33$ & $471 \pm 26$ & $474 \pm 34$ \\
$(\mu$ mol/g wet tissue) & $24 h^{\ddagger}$ & $508 \pm 38$ & $531 \pm 40$ & $487 \pm 33$ \\
\hline
\end{tabular}

Values are means \pm SD. CON; distilled water. SUC; $5 \%$ sucrose solution. GLU; $5 \%$ glucose solution. Significant effect of recovery time, ${ }^{\ddagger} ; \mathrm{p}<0.001$, vs. $6 \mathrm{~h}$ 


\section{Muscle glycogen concentration.}

A 4-h swimming exercise reduced glycogen concentration in rat epitrochlearis muscle to a level of $5 \pm 3 \mu \mathrm{mol} / \mathrm{g}$ wet tissue from pre-exercise value of $46 \pm 11 \mu \mathrm{mol} / \mathrm{g}$ wet tissue.

Muscle glycogen concentration in epitrochlearis of the GLU $(p<0.001)$ and SUC $(p<0.05)$ groups were significantly higher than that observed in the CON group (Fig.1). Moreover, glucose supplementation induced significantly higher glycogen accumulation compared with sucrose $(\mathrm{p}<0.01)$. There was not significant difference in glycogen concentration between $6 \mathrm{~h}$ and $24 \mathrm{~h}$. The interaction between different types of sugar supplementation and time for recovery was not statistically significant.

\section{Liver glycogen concentration.}

Pre-exercise liver glycogen concentration was $134 \pm 19 \mu \mathrm{mol} / \mathrm{g}$ wet tissue, which decreased to $17 \pm 3 \mu \mathrm{mol} / \mathrm{g}$ wet tissue after the glycogen-depleting swimming exercise.

Liver glycogen concentration was not affected by the different types of sugar supplementation (Table 3). Hepatic glycogen level after $24 \mathrm{~h}$ recovery period was significantly higher than that observed after $6 \mathrm{~h}$ recovery period $(p<0.001)$. No statistically significant interaction between different types of sugar supplementation and time for recovery was observed.

\section{DISCUSSION}

The present investigation demonstrated that glucose supplementation efficiently promotes glycogen supercompensation in rat skeletal muscle.

Dietary carbohydrate is absorbed by the small intestine via the stomach. Several studies suggested that there were circadian rhythms of intestinal sugar absorption in rats (Fisher and Gardner 1976, Furuya and Yugari 1974). In our study, therefore, rats were allowed to access to Purina chow and drinks ad libitum instead of injection using by a gastric tube. As a result, food and fluid consumption in the $\mathrm{CON}$ group were significantly higher compared with that observed in the GLU and SUC groups. Total carbohydrate intake reckoned from food and fluid consumption in the CON group during 24 $\mathrm{h}$ recovery period was not different compared with those observed in GLU and SUC groups (17.2 $\pm 1.2 \mathrm{~g}$; CON, $18.2 \pm 0.7 \mathrm{~g} ;$ CLU, $18.2 \pm 0.6 \mathrm{~g}$; SUC, respectively). Therefore, we consider that, among the three groups, the differences in replenished glycogen content are induced by some factor except for the amount of carbohydrates absorbed during recovery period.

\section{Muscle glycogen}

In our data, total carbohydrate intake during recovery period was not different among the three groups, nevertheless the muscle glycogen concentration in the GLU group was significantly higher than that observed in other two groups after recovery period. Pancreatic insulin secretion to absorbed glucose should be greater than that by sucrose, because glycemic index of glucose is known to be higher than sucrose (approx. 65, as described by Foster-Powell and Miller 1995). Insulin stimulates glucose uptake and glycogen synthase activity in skeletal muscle. Therefore, we speculated that glucose supplementation highly induces muscle glycogen 
resynthesis followed by a large amount of pancreatic insulin secretion. However, plasma insulin concentration did not differ among three groups (Table 2). In the present study, rats were allowed to access to food and drinks ad libitum, which might cause lots of variability in insulin concentration.

There were two human studies that determined the efficacy of glucose and sucrose drinks in promoting muscle glycogen resynthesis during the early phase (2- to 6-h) of recovery from exhaustive exercise (Blom et al. 1987, Bowtell et al. 2000). Since, in those studies, muscle glycogen after the recovery period was still below the pre-exercise level, it is unclear which type of sugar is effective to induce higher muscle glycogen level when it is fully recovered. Our study has first demonstrated that glucose supplementation rather than sucrose efficiently enhanced the level of glycogen supercompensation in skeletal muscle after exercise

In the present study, we adopted standard rodent chow of which carbohydrate was mainly contained as starch. Though total $\mathrm{CHO}$ intake in the three groups during recovery period was not different, the content of glucose or sucrose supplementation was only $\sim 20 \%$ in the total $\mathrm{CHO}$ intake. It would be interesting to examine the effect of high-glucose or high-sucrose diet on glycogen supercompensation.

\section{Liver glycogen}

It has not been clear which type of sugar is effective to attain higher glycogen level in liver when it is fully recovered. Conlee et al. (1987) evaluated liver glycogen concentration $4 \mathrm{~h}$ after exercise when rats were fed either glucose or fructose by gastric tube immediately after exercise and demonstrated that fructose induced a significantly greater glycogen storage than glucose after $4 \mathrm{~h}$ recovery period. Sucrose is a disaccharide containing glucose and fructose, and fructose is largely metabolized in the liver (Zakim et al. 1969). In the present study, we therefore hypothesized that consumption of sucrose during recovery enhances glycogen supercompensation in liver. However, no significant difference was observed in the liver glycogen concentration among the three groups (Table 3 ). These results may provide possibility that different types of sugar supplementation did not affect liver glycogen supercompensation after exercise.

\section{SUMMARY}

In conclusion, glucose supplementation after glycogen-depletion endurance exercise more efficiently promotes glycogen supercompensation than sucrose in trained-rat skeletal muscle.

\section{REFERENCE}

- Ahlborg B, Bergstrom J, Brohult J, Ekelund LG, Hultman E, Maschio G. (1967) Human muscle glycogen content and capacity for prolonged exercise after different diets. Forsvarsmedicin, 3, 85-99

- Bergstrom J, Hermansen L, Hultman E, Saltin B. (1967) Diet, muscle glycogen and physical performance. Acta Physiol Scand., 71(2), 140-50

- Bergstrom J, Hultman E. (1966) Muscle glycogen synthesis after exercise: an enhancing factor localized to the muscle cell in man. Nature, 210, 309-310

- Blom PC, Hostmark AT, Vaage O, Kardel 
KR, Maehlum S. (1987) Effect of different post-exercise sugar diets on the rate of muscle glycogen synthesis. Med Sci Sports Exerc. 19(5):491-6.

- Bowtell JL, Gelly K, Jackman ML, Patel A, Simeoni M, Rennie MJ. (2000) Effect of different carbohydrate drinks on whole body carbohydrate storage after exhaustive exercise. J Appl Physiol. 88(5):1529-36.

- Cartee GD, Young DA, Sleeper MD, Zierath J, Wallberg-Henriksson H, Holloszy JO. (1989) Prolonged increase in insulin-stimulated glucose transport in muscle after exercise. Am J Physiol., 256, E494-499

- Conlee RK, Lawler RM, and Ross PE. (1987) Effects of glucose or fructose feeding on glycogen repletion in muscle and liver after exercise or fasting. Ann Nutr Metab., 31, 126-32

- Fisher RB, Gardner ML. (1976) A diurnal rhythm in the absorption of glucose and water by isolated rat small intestine. $\mathrm{J}$ Physiol., 254(3), 821-5

- Foster-Powell K, Miller JB. (1995) International tables of glycemic index. Am J Clin Nutr., 62(4), 871S-890S, Review.

- Furuya S, Yugari Y. (1974) Daily rhythmic change of L-histidine and glucose absorptions in rat small intestine in vivo. Biochim
Biophys Acta, 343(3), 558-64

- Lowry OH, Passoneau JV. (1972) A Flexible System of Enzymatic Analysis. Academic Press, New York.

- Nakatani A, Han DH, Hansen PA, Nolte LA, Host HH, Hickner RC, Holloszy JO. (1997) Effect of endurance exercise training on muscle glycogen supercompensation in rats. J Appl Physiol., 82(2), 711-5

- Ren JM, Semenkovich CF, Gulve EA, Gao J, Holloszy JO. (1994) Exercise induces rapid increases in GLUT4 expression, glucose transport capacity, and insulin-stimulated glycogen storage in muscle. J Biol Chem., 269(20), 14396-401

- Terada S, Yokozeki T, Kawanaka K, Ogawa K, Higuchi M, Ezaki O, Tabata I. (2001) Effects of high-intensity swimming training on GLUT-4 and glucose transport activity in rat skeletal muscle. J Appl Physiol., 90(6), 2019-24

- Young DA, Wallberg-Henriksson H, Sleeper MD, Holloszy JO. (1987) Reversal of the exercise-induced increase in muscle permeability to glucose. Am J Physiol., 253, E331-335

- Zakim D, Herman RH, Gordon WC. (1969) The conversion of glucose and fructose to fatty acids in the human liver. Biochem. Med., 2, 427-437 